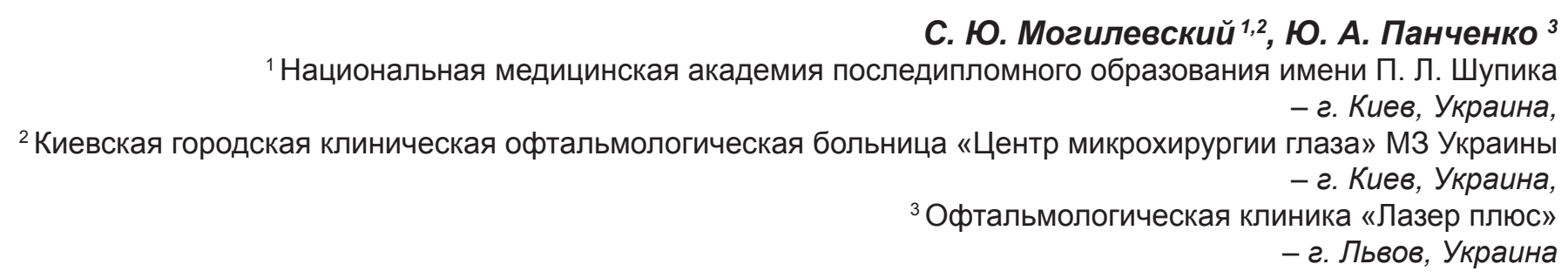

\title{
ОСОБЕННОСТИ ДИАБЕТИЧЕСКОЙ МАКУЛОПАТИИ У БОЛЬНЫХ САХАРНЫМ ДИАБЕТОМ 2-ГО ТИПА
}

\begin{abstract}
В статье приведены результаты исследования особенностей диабетической макулопатии у больных (361 глаз) сахарным диабетом 2-го типа. Установлено, что частота диабетической макулопатии составила $72,6 \%$, диабетического макулярного отёка $-46,0 \%$. Их частота не отличалась ни при умеренной и тяжёлой непролиферативной диабетической ретинопатии, ни при пролиферативной диабетической ретинопатии. Частота диабетической макулопатии зависела от продолжительности диабета, в то же время от диабетического макулярного отёка не зависела. Установлено, что их частота была статистически значимо ниже в группе 51-60 лет и не отличалась в группах до 40 лет, 41-50 лет, 61-70 лет, 71 год и старше.
\end{abstract}

Ключевые слова: диабетическая ретинопатия, диабетическая макулопатия, диабетический макулярный отёк.

В настоящее время количество больных сахарным диабетом (СД) увеличивается вдвое каждые 12-15 лет, что даёт основание экспертам говорить о его глобальной эпидемии. Согласно данным Всемирной организации здравоохранения, в 2016 году сахарным диабетом в мире болело 422 млн человек. По данным Международной диабетической федерации (IDF), к 2030 году страдать от диабета в мире будет 552 млн человек, то есть 9,9\% населения планеты [14].

Около 90\% всей популяции больных СД составляют больные СД 2-го типа (СД2). СД2 часто называют «болезнью цивилизации». Исследователями отмечено не только большее распространение СД2 по сравнению с СД 1-го типа (СД1), но и инвалидизация в более короткие сроки вследствие его офтальмологических осложнений $[4,16]$.

Наиболее грозным осложнением СД2 со стороны органа зрения является диабетическая ретинопатия (ДР). ДР, а также диабетическую нефропатию и диабетическую стопу ВООЗ определила в качестве профилактики и лечения осложнений СД2. В 2010 году в мире было зарегистрировано 126,6 млн пациентов с ДР; до 2030 года их количество может вырасти до 191 млн [16]. ДР составляет 1\% в структуре слепоты и $1 \%$ в структуре слабовидения в мире и занимает первое место среди причин слепоты в развитых странах $[2,14]$.

Распространение диабетической ретинопатии среди населения трудоспособного возраста в Украине в 2017 году составило 231,7 человек на 100000 населения, среди людей пенсионного возраста $-914,4$ на 100000 [6].
Развитие диабетической макулопатии (ДМП) и диабетического макулярного отёка (ДМО) у больных ДР приводит к значительному прогрессирующему снижению зрительных функций. Частота ДМП и ДМО коррелируют со степенью тяжести СД, проводимой инсулинотерапией, а также типом СД (при СД2 она значительно возрастает). Есть данные о влиянии на частоту и выраженность ДМП и ДМО продолжительности СД и стадии ДР $[1,5,8,9,11,13]$. К факторам риска также относят гипергликемию, гиперхолестеринемию, гипертоническую болезнь, нефропатию, хирургическое лечение катаракты [5].

Главными звеньями диабетической макулопатии, по мнению Л.И. Балашевича и А.С. Измайлова (2012 г.), являются отёк сетчатки в зоне жёлтого пятна вследствие увеличения проницаемости ретинальных сосудов и ретинальная ишемия в результате капиллярной и артериальной перфузии сетчатки. Причиной развития ДМО считается повышение проницаемости внутреннего гемато-офтальмического барьера, которое возникает как результат нарушения функционирования эндотелиальных клеток сосудов сетчатки при сахарном диабете. Играет роль и взаимодействие гидростатического и онкотического давления между плазмой внутри капилляров и межклеточными пространствами сетчатки. Есть данные о роли в развитии ДМО нарушения функций пигментного эпителия сетчатки $[2,7,12]$. Это подтверждается данными экспериментальных исследований [15].

Цель исследования - изучить особенности диабетической макулопатии у больных сахарным диабетом 2-го типа. 
Материалы и методы. Под нашим наблюдением находился 361 больной (361 глаз; 125 мужчин, 236 женщин) с сахарным диабетом 2-го типа и ДР различного уровня тяжести. Возраст больных составил 39-75 лет. Продолжительность СД2 была от 1 года до 36 лет. У 276 больных СД2 был компенсирован, у 52 субкомпенсирован, у 33 - декомпенсирован. 328 больных с компенсированным и субкомпенсированным СД2 принимали таблетированные сахаропонижающие препараты, 33 больных с декомпенсированным СД2 - сочетание таблетированных сахаропонижающих препаратов и инсулинотерапии. 147 больных $(40,72 \%)$ с целью нормализации липидного обмена принимали статины или фибраты.

В исследование не включали больных, которые ранее перенесли тромбоз центральной вены сетчатки или её ветвей, задний увеит, центральную серозную хориопатию, а также больных с афакией и артифакией и больных, страдающих первичной или вторичной глаукомой, хроническими инфекционными болезнями и интоксикациями, анемиями, лейкозами геморрагическими диатезами.

Всем больным были выполнены общепринятые офтальмологические исследования, включающие визометрию, статическую периметрию Humphrey, рефрактометрию, тонометрию, биомикроскопию, гониоскопию, офтальмоскопию с помощью асферической линзы Volk Super/Field (США) и контактной трёхзеркальной линзы Гольдмана. Всем больным выполняли спектральнодоменную оптическую когерентную томографию (ОСТ) на приборе Optopoltechnology, SOCT, Copernicus REVO (протокол Retina3D, Retina Raster) и ОСТ в режиме «Ангио» (протокол Retina Angio, wide $6 \times 6 \mathrm{~mm}$ ). Также выполняли исследование глазного дна на фундус-камере с его фотографированием в 7 стандартных полях в соответствии с модифицированной ETDRS системой клинических признаков Airlie House. Флуоресцентную ангиографию (ФАГ) выполняли по показаниям (в случае подозрения на скрытую неоваскуляризацию не идентифицированную офтальмоскопически и по фотографиям глазного дна, а также в случае несоответствия зрительных функций офтальмоскопическим изменениям в макулярной области или данным ОСТ).

Уровень тяжести ДР устанавливали в соответствии с Интернациональной клинической шкалой тяжести диабетической ретинопатии Американской академии офтальмологии (2002 г.). Уровень тяжести ДМП устанавливали в соответствии с Интернациональной клинической шкалой тяжести диабетической макулопатии Американской академии офтальмологии (2002 г.).

Было создано три группы наблюдения:

- 1-ая группа - нет ДР, начальная НПДР;

- 2-ая группа - умеренная и тяжёлая НПДР;

- 3-я группа - ПДР.
Количество глаз 1-ой, 2-ой и 3-ей групп наблюдения было 80, 175 и 106 соответственно.

Изучали частоту ДМП и ДМО в зависимости от пола, возраста, стадии ДР, а также длительности СД2.

ДМП устанавливали при наличии специфических диабетических изменений сетчатки в макулярной области: микроаневризм, геморрагий, интраретинальных микрососудистых аномалий, витреоретинальной сосудистой пролиферации. Наличие ишемической формы ДМП устанавливали при расширении сосудистой аваскулярной зоны и/или наличии зон капиллярной окклюзии в макулярной области по данным ангио-ОСТ и/или ФАГ. ДМО устанавливали при увеличении толщины сетчатки больше значений нормативной базы данных по полям ETDRS программного обеспечения спектральнодоменного ОСТ (отмечалось цветовой шкалой, что подтверждало увеличение толщины сетчатки за пределы нормы - жёлтым - $<<0,05$ или красным цветом $\mathrm{p}<0,01$ ). Увеличение толщины сетчатки отмечали как без, так и с нарушением архитектоники (кистозные полости в нейроэпителии, отслойка нейроэпителия, гиперрефлективные включения на уровне нейроэпителия, соответствующие твёрдым экссудатам, нарушение архитектоники внутренних слоёв сетчатки, соответствующие интраретинальным кровоизлияниям или «ватным» экссудатам).

Для точной оценки выраженности ДМО и его степени тяжести мы использовали «Характеристику изменений морфологии сетчатки по данным спектральнодоменного ОСТ при ДМО», разработанную нами ранее [10].

При проведении анализа результатов исследования для представления качественных признаков рассчитывалась частота (p, \%) и её стандартная ошибка ( $\pm \mathrm{m} \%)$ [3]. При сравнении качественных признаков использовался критерий $\xi$-квадрат (с поправкой Йейтса) для сравнения двух групп; при сравнении трёх и более групп учитывалась поправка на множественные сравнения; при сравнении упорядоченных градаций использовался критерий $\xi$-квадрат для выявления тренда [3]. Критический уровень значимости принят равным 0,05 .

Результаты и их обсуждение. При обследовании больных с ДР и СД2 было установлено, что частота ДМП составила $72,6 \%$, а частота ДМО - 46,0\%. Частота ДМО у больных с ДМП составила 63,0\%. При исследовании зависимости частоты ДМП и ДМО у больных СД2 от стадии ДР было установлено следующее. Частота ДМП и ДМО статистически значимо зависела от стадии ДР. Была отмечена тенденция к некоторому увеличению частоты ДМП и ДМО у больных с пролиферативной диабетической ретинопатией (ПДР) ( $\mathrm{p}=0,7$ и $\mathrm{p}=0,62$ соответственно). Это отражает табл. 1. 
Зависимость частоты ДМП и ДМО у больных СД2 от стадии ДР (в \%, P \pm m)

\begin{tabular}{|c|c|c|c|c|}
\hline & \multirow{2}{*}{$\begin{array}{l}\text { Всего, } \\
n=361\end{array}$} & 1-я группа наблюдения & 2-я группа наблюдения & 3-я группа наблюдения \\
\hline & & $\begin{array}{c}\text { нет ДР, начальная } \\
\text { НПДР, } n=80\end{array}$ & $\begin{array}{c}\text { умеренная и тяжёлая } \\
\text { НПДР, } n=175\end{array}$ & $\begin{array}{c}\text { ПДР, } \\
n=106\end{array}$ \\
\hline ДМП & $\begin{array}{c}262 \\
(72,6 \pm 2,3)\end{array}$ & $\begin{array}{c}0 \\
(0)\end{array}$ & $\begin{array}{c}161 \\
(92,0 \pm 2,1)\end{array}$ & $\begin{array}{c}101 \\
(95,3 \pm 2,1)\end{array}$ \\
\hline $\mathrm{p}$ & & $\mathrm{p}_{1-2}<0,001$ & $\mathrm{p}_{2-3}=0,70$ & $\mathrm{p}_{1-3}<0,001$ \\
\hline В том числе: ДМО & $\begin{array}{c}166 \\
(46,0 \pm 2,6)\end{array}$ & $\begin{array}{c}0 \\
(0)\end{array}$ & $\begin{array}{c}99 \\
(56,6 \pm 3,7)\end{array}$ & $\begin{array}{c}67 \\
(63,2 \pm 4,7)\end{array}$ \\
\hline $\mathrm{p}$ & & $\mathrm{p}_{1-2}<0,001$ & $\mathrm{p}_{2-3}=0,62$ & $\mathrm{p}_{1-3}<0,001$ \\
\hline
\end{tabular}

Примечание: при проведении апостериорных сравнений использована процедура Мараскуилло (МЛГ)

Таблииа 2

Зависимость частоты ДМП и ДМО у больных ДР от продолжительности СД2 (в \%, $\mathrm{P} \pm \mathrm{m})$

\begin{tabular}{|c|c|c|c|c|c|}
\hline & До 3-х лет & $3-5$ лет & $6-10$ лет & 11-20 лет & 21 год и больше \\
\cline { 2 - 6 } & $n=50$ & $n=68$ & $n=98$ & $n=129$ & $n=16$ \\
\hline \multirow{2}{*}{ ДМП } & 23 & 45 & 65 & 115 & 14 \\
& $(46,0 \pm 7,0)$ & $(66,2 \pm 5,7)$ & $(66,3 \pm 4,8)$ & $(89,1 \pm 2,7)$ & $(87,5 \pm 8,3)$ \\
\hline $\mathrm{p}$ & 17 & $<0,001$ & 62 & 8 \\
\hline \multirow{2}{*}{ ДМО } & $(34,0 \pm 6,3)$ & $(48,5 \pm 6,1)$ & $(46,9 \pm 0)$ & $(48,1 \pm 4,4)$ & $(50,0 \pm 12,5)$ \\
\hline $\mathrm{p}$ & \multicolumn{5}{|c|}{} \\
\hline
\end{tabular}

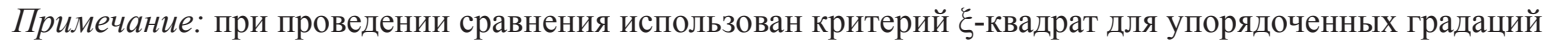

Таблицуа 3

Зависимость частоты ДМП и ДМО у больных ДР и СД2 от пола и возраста (в \%, P \pm m)

\begin{tabular}{|c|c|c|c|c|c|c|}
\hline & & & ДМП & $p$ & $\begin{array}{c}\text { В том числе: } \\
\text { ДМО }\end{array}$ & $p$ \\
\hline \multirow{2}{*}{ 它 } & мужчины & $\begin{array}{c}n=125 \\
(34,6 \pm 2,5)\end{array}$ & $\begin{array}{c}87 \\
(69,6 \pm 4,1) \\
\end{array}$ & \multirow{2}{*}{0,43} & $\begin{array}{c}52 \\
(41,6 \pm 4,4) \\
\end{array}$ & \multirow{2}{*}{0,27} \\
\hline & женщиины & $\begin{array}{c}n=236 \\
(65,4 \pm 2,5)\end{array}$ & $\begin{array}{c}175 \\
(74,2 \pm 2,8)\end{array}$ & & $\begin{array}{c}114 \\
(48,3 \pm 3,3)\end{array}$ & \\
\hline \multirow{5}{*}{$\begin{array}{l}\tilde{0} \\
\tilde{0} \\
\tilde{0} \\
\text { ஜn }\end{array}$} & до 40 лет включительно & $\mathrm{n}=4$ & $\begin{array}{c}3 \\
(75 \pm 22)\end{array}$ & \multirow{5}{*}{0,005} & $\begin{array}{c}2 \\
(50 \pm 25)\end{array}$ & \multirow{5}{*}{$<0,001$} \\
\hline & 41-50 лет & $\mathrm{n}=21$ & $\begin{array}{c}15 \\
(71,4 \pm 9,9) \\
\end{array}$ & & $\begin{array}{c}8 \\
(38,1 \pm 10,6) \\
\end{array}$ & \\
\hline & 51-60 лет & $\mathrm{n}=93$ & $\begin{array}{c}55 \\
(59,1 \pm 5,1)\end{array}$ & & $\begin{array}{c}27 \\
(29,0 \pm 4,7)\end{array}$ & \\
\hline & 61-70 лет & $\mathrm{n}=149$ & $\begin{array}{c}122 \\
(81,9 \pm 3,2)\end{array}$ & & $\begin{array}{c}86 \\
(57,7 \pm 4,0)\end{array}$ & \\
\hline & 71 год и старше & $\mathrm{n}=94$ & $\begin{array}{c}67 \\
(71,3 \pm 4,7)\end{array}$ & & $\begin{array}{c}43 \\
(45,7 \pm 5,1)\end{array}$ & \\
\hline
\end{tabular}

Примечание: при проведении апостериорных сравнений при анализе по возрасту использована

процедура Мараскуилло (МЛГ)

Нами также была изучена зависимость частоты ДМП и ДМО у больных ДР от продолжительности СД2. Эту зависимость отражает табл. 2.

Как видно из табл. 2, частота ДМП у больных ДР зависела от продолжительности СД2 (отмечено наличие положительного тренда, $\mathrm{p}<0,01)$. Частота ДМО также зависела от продолжительности СД2, однако эта зависимость не была статистически значимой (было отмечено отсутствие тренда, $p=0,37$ ).
Также нами была изучена зависимость частоты ДМП и ДМО у больных ДР и СД2 от пола и возраста. Эта зависимость представлена в табл. 3.

При указанном в табл. 3 методе анализа установлено, что частота ДМП и ДМО не зависела от пола пациентов ДР и СД2. Частота ДМП и ДМО не зависела от возраста пациентов в группах до 40 лет включительно, 41-50 лет, 61-70 лет, 71 и старше и была значимо ниже в группе 51-60 лет. 
Полученные нами данные лишь отчасти согласуются с данными других исследователей $[2,4,5,11]$. Так, в наших исследованиях частота ДМП и ДМО не отличалась в группах с НПДР и ДР, частота ДМП зависела от продолжительности СД2, а ДМО - не зависела. Также представляют интерес полученные нами данные о более низкой частоте этих осложнений у больных с ДР 51-60 лет.

Хотелось бы отметить, что многие исследователи отождествляют понятия ДМП и ДМО. В этом плане мы разделяем точку зрения Л.И. Балашевича и А.С. Измайлова (2012 г.), которые указывали, что ДМО является более узким понятием, чем ДМП. Именно поэтому в нашем исследовании мы отдельно оценивали ДМП и ДМО. Во всех случаях ДМО сопровождался признаками ДМП; в целом ряде случаев ДМП не сопровождалась макулярным отёком.

\section{Выводы}

1. Частота ДМП и ДМО при данном объёме исследований составила 72,6\% и 46,0\% соответственно. Частота ДМО у больных ДМП составила 63,0\%.

2. Частота ДМП и ДМО не отличалась при умеренной и тяжёлой НПДР и ПДР.

3. Установлена статистически значимая зависимость частоты ДМП от продолжительности СД2. Частота ДМО не была связана с продолжительностью СД2.

4. Зависимости ДМП и ДМО от возраста больных ДР и СД2 установлено не было. В группе 51-60 лет их частота была значительно ниже $(\mathrm{p}<0,01)$.

5. Изучение новых патогенетических механизмов ДМП и ДМО позволит дать объяснение полученным результатам нашего исследования.

\section{Литература}

1. Братко Г. В. Частота встречаемости макулярного отёка и группы риска его формирования / Г. В. Братко, О. В. Сазонова, М. В. Ковалева [и др.] // Современные технологии в офтальмологии. 2016. - № 2. - С. 90-92.

2. Варивончик Д. В. Світові епідеміологічні характеристики поширеності порушень зору / Д. В. Варивончик // Офтальмологія. - 2016. - № 1 (03). - C. 12-22.

3. Гур'янов В. Г. Посібник з біостатистики. Аналіз результатів медичних досліджень у пакеті EZR (R-statistics): навчальний посібник / В. Г. Гур'янов, Ю. Є. Лях, В. Д. Парій [та ін.]. - К.: Вістка, 2018. - 208 c.

4. Дедов И. И. Инновационные технологии в лечении и профилактике сахарного диабета и его осложнений / И. И. Дедов // Сахарный диабет. 2013. - Т. 16, № 3. - С. 4-10.
5. Диабетическая офтальмопатия / Под ред. Л. И. Балашевича, А. С. Измайлова. - СПб.: Человек, 2012. - 396 c.

6. Моісеєнко P. O. Офтальмологічна допомога в Україні за 2014-2017 роки: Аналітично-статистичний довідник / Р. О. Моісеєнко, М. В. Голубчиков, В. М. Михальчук [та ін.] - Кр-й: «ПОЛІУМ», 2018. - 314 c.

7. Нероев В. В. Современные аспекты лечения диабетической ретинопатии и диабетического макулярного отёка / В. В. Нероев // Вестник Российской академии медицинских наук. - 2012. - № 1. - С. 61-65.

8. Пасечникова H. B. Диабетическая макулопатия. Современные аспекты патогенеза, клиники, диагностики, лечения / Н. В. Пасечникова, С. А. Сук, Т. А. Кузнецова, О. Г. Пархоменко. - К.: «Карбон ЛТД», 2010. - 154 с.

9. Рыков С. А. Особенности диагностики морфологических разновидностей диабетического макулярного отёка по данным спектральной оптической когерентной томографии / С. А. Рыков, С. А. Сук, О. Г. Пархоменко [и др.] // Ендокринологія. - 2013. - T. 18, № 4. - С. 28-31.

10. Рыков C. А. Усовершенствованный алгоритм анализа снимков оптической когерентной томографии макулярной области сетчатки при диабетическом макулярном отёке / С. А. Рыков, С. Ю. Могилевский, О. Г. Пархоменко [и др.] // Архів офтальмології України. - 2015. - Т. 3, № 1. - С. 40-47.

11. Сорокин E. Л. Выяснение последовательности формирования диффузного диабетического макулярного отёка при сахарном диабете 2-го типа / Е. Л. Сорокин, О. В. Коленко, М. В. Пшеничнов [и др.] // Вестник Оренбургского государственного университета. - 2012. - № 12 (148). - С. 187-190.

12. Bresnick G. H. Diabetic maculopathy. A critical review highlighting diffuse macular edema / G. H. Bresnick // Ophthalmology. - 1983. - Vol. 93, № 7. - P. 989-997.

13. Chen E. Burden of illness of diabetic macular edema: literature review / E. Chen // Curr. Med. Res. Opin. 2010. - Vol. 26, № 7. - P. 1587-1597.

14. Global data on visual impairments: 2010 [Electronic resource] / WHO. - 2012. - 17 p. - Available at: http://www.who.int/blindness/GLOBALDATAFINALforweb.pdf?ua $=1$.

15. Tso M. O. M. Experimental macular edema after lens extraction / M. O. M. Tso // Invest. Ophthalmol. Vis. Sci. - 1977. - Vol. 16. - P. 381-382.

16. Zheng $Y$. The worldwide epidemic of diabetic retinopathy / Y. Zheng, M. He, N. Congdon // Indian Journal of Ophthalmology. - 2012. - Vol. 60 (5). - P. 428-231. 


\title{
ОСОБЛИВОСТІ ДІАБЕТИЧНОЇ МАКУЛОПАТІЇ У ХВОРИХ НА ЦУКРОВИЙ ДІАБЕТ 2-ГО ТИПУ
}

\section{С. Ю. Могілевський, Ю. О. Панченко}

У статті наведено результати дослідження особливостей діабетичної макулопатії у хворих (361 око) на цукровий діабет 2-го типу. Встановлено, що частота діабетичної макулопатії склала 72,6\%, діабетичного макулярного набряку - 46,0\%. Їхня частота не відрізнялася ні при помірній та тяжкій непроліферативній діабетичній ретинопатії, ні при проліферативній діабетичній ретинопатії. Частота діабетичної макулопатії залежала від тривалості діабету, від діабетичного макулярного набряку не залежала. Встановлено, що їхня частота була статистично значимо нижчою в групі 51-60 років і не відрізнялася в групах до 40 років, 41-50 років, 61-70 років, 71 рік і старше.

Ключові слова: діабетична ретинопатія, діабетична макулопатія, діабетичний макулярний набряк.

\section{DIABETIC MACULOPATHY CHARACTERISTICS IN PATIENTS WITH TYPE 2 DIABETES}

\author{
S. Yu. Mogilevskyy ${ }^{1,2}$, Yu. O. Panchenko ${ }^{3}$ \\ ${ }^{1}$ National Medical Academy of Postgraduate Education named after P. L. Shupyk \\ Kyiv, Ukraine, \\ ${ }^{2}$ Kyiv City Clinical Ophthalmological Hospital "Eye Microsurgery Center" \\ of the Ministry of Public Health of Ukraine \\ Kyiv, Ukraine, \\ ${ }^{3}$ LASER Plus Eye clinic \\ Lviv, Ukraine
}

The results of the assessment of diabetic maculopathy in patients with type 2 diabetes are presented (data of 361 studied eyes). The frequency of diabetic maculopathy is equal to $72,6 \%$, the frequency of diabetic macular edema $46,0 \%$. There was no association of the rate of occurrence of diabetic maculopathy and diabetic macular edema with mild or severe non-proliferative diabetic retinopathy and with proliferative diabetic retinopathy. The frequency of diabetic maculopathy was associated with terms of diabetes, while the frequency of diabetic macular edema was not. Their frequency was statistically significant in groups of patients of 51-60 years old, and did not differ in groups of patients younger than 40, 41-50, 61-70 and 71 and older.

Key words: diabetic retinopathy, diabetic maculopathy, diabetic macular edema.

Стаття надійшла до редакції 15.07.2018 p.

С. О. Риков, О. А. Венедіктова

Національна медична академія післядипломної освіти імені П. Л. Шупика

- м. Київ, Україна

УДК 617.7-07-06:[616.126.32:616.132:616.132.2]-089.86-089.166-089.5:615.381

\section{ОКЛЮЗІї СУДИН СІТКІВКИ \\ ПІСЛЯ КАРДІОХІРУРГІЧНИХ ВТРУЧАНЬ \\ I3 ВИКОРИСТАННЯМ ШТУЧНОГО КРОВООБІГУ}

Значною групою ризику виникнення оклюзій судин сітківки є пацієнти з серцево-судинними захворюваннями. Сьогодні лікування хворих з вродженими та набутими вадами серця, ішемічною хворобою серця (IXC) неможливе без хірургічних втручань, більшість яких потребує використання штучного кровообігу (ШК). Під час операції ШК внаслідок тривалої гіпотермії, гемодилюції, пролонгованої гіпотензії та анемії можливий розвиток офтальмологічних ускладнень у ранньому післяопераційному періоді. Нами було проведене офталь- 